\title{
Teacher self-efficacy and teacher burnout: A study of relations
}

\author{
Leila Gholami, M.A. Student in TEFL \\ Kharazmi University, Iran \\ Corresponding Author: I.gholami12@gmail.com
}

\section{Keyword: teacher self-efficacy, teacher burnout}

\begin{abstract}
In any teaching and learning setting, there are some variables that play a highly significant role in both teachers' and learners' performance. Two of these influential psychological domains in educational context include self-efficacy and burnout. This study is conducted to investigate the relationship between the self-efficacy of Iranian teachers of English and their reports of burnout. The data was collected through application of two questionnaires. The Maslach Burnout Inventory (MBI; Maslach\& Jackson 1981, 1986) and Teacher Efficacy Scales (Woolfolk\& Hoy, 1990) were administered to ten university teachers. After obtaining the raw data, the SPSS software (version 16) was used to change the data into numerical interpretable forms. In order to determine the relationship between self-efficacy and teachers' burnout, correlational analysis was employed. The results showed that participants' self-efficacy has a reverse relationship with their burnout.
\end{abstract}

\section{INTRODUCTION}

Teacher's self-efficacy and its relation with teacher burnout have received considerable research interest in recent years. It is generally accepted that these two features significantly affect teaching and learning situations.

\subsection{Teacher burnout}

Burnout is defined as a consequence of long term occupational anxiety, specifically among human service worker, including teachers (Jennett, Harris, \& Mesibove, 2003). Quite many teachers may experience stress in their work, while the reasons behind this phenomenon are diverse (Jennett et al., 2003). As a matter of fact, some teachers can handle stress successfully, whereas others may not be able to handle it (Jennett et al., 2003).

\subsection{Teacher self-efficacy}

The theory of self-efficacy lies at the center of Bandora's social cognitive theory. Bandora (2006) has defined self-efficacy as one's faith in one's capacity to succeed in particular circumstances. Our perception of environmental opportunities is determined by efficacy beliefs (Bandora, 2006a) and it influences the amount of exertion is used on an action, and the extent to which any typical individual would preserve when confronting obstacles (Pajares, 1997).

In spite of the large body of research done, it is not clear why a few instructors succeed in being good educator, in constantly improving students' accomplishments, and in achieving their own goals, while others cannot meet expectations imposed on them and have a tendency to crumple under the load of regular anxiety. One possible explanation lies in a teacher's self-efficacy as a job specific disposition. Scholars suggest that lack of sense of mastery (i.e., self-efficacy) in teachers eventually results in their inability of adaptation and consequently their being burnout (Chwalisz, Altmaier \& Russell, 1992; Brouwers \& Tomic, 2000). This study tries to shed more light on burnout process by taking into account the self-efficacy factor among EFL teachers. This study aims at investigating Iranian EFL teachers' self-efficacy and its relation to their burnout. Therefore, this study addresses the following research question.

Is there any significant relationship between teachers' self-efficacy beliefs and reports of burnout?

\section{METHOD}

\subsection{Participants}

The participants in this study consisted of 10 EFL educators from Urmia University, Iran (3 females and 7 males) aged between 30 and +50 years old with a range of between 2 and +10 years 
of teaching experience. The participants were selected from available subjects and they had professional experience of teaching EFL at University levels. They were from various age groups and different years of experiences. Their field of study was TEFL ( 2 females, 5 males), English Translation (1 male), and English Literature (1 male \& 1 female).

\subsection{Instruments}

Two questionnaires of Burnout and self-efficacy were applied in this study, and demographic form asked about the participants' demographic information including age, gender, and years of teaching experience.

\subsubsection{Teacher's burnout scale}

Burnout scale (22items). The Maslach Burnout Inventory (MBI), a 22-item Likert-type scale, was used as a measure of teacher burnout (Maslach, Jackson, \& Leiter, 1996). Inventory consisted of three subscales: Exhaustion (EE: 9 items), Depersonalization (D: 5 items), and accomplishment (A: 8items). Higher emotional exhaustion, depersonalization and lower personal accomplishment lead to high burnout status. Reliability coefficient for the inventory was calculated employing a Cronbach Alpha which was found as ....Exploratory factor analyses demonstrated a satisfactory factor structure for the scale considered in the study. These three burnout dimensions have already been confirmed in factor analytic studies (Schaufeli \& Van Dieredock, 1993).

\subsubsection{Teacher self-efficacy}

In order to evaluate teacher's self-efficacy, the adopted version of Teacher Efficacy scale (Woolfolk \& Hoy, 1990) was used. A principal-components factor analysis, with Varimax rotation, was carried out on 10 items to determine whether they represented these constructs.

This analysis revealed two factors that accounted for $55.1 \%$ of the total variance. The resultant index also presented satisfactory internal consistency (Cronbach's alpha: 0.75). All teacher responses were scored on a six-point Likert-type scale, with response options ranging from 1 (strongly agree) to 4 (strongly disagree). In this scale, the higher scores were considered to mean greater sense of efficacy among teachers. The questionnaires were distributed to 10 professors in the first half of the academic year before the term-break. The professors were asked to complete questionnaires on the university premises. No name or identification number was required, thereby mentioning anonymity. The frequency of the feeling represented by each item on a 6-point Likertscale (MBI) was scored by assigning 1 to 6 . The same scoring procedure was used with the efficacy questionnaire. The statistical analysis of the data was done using Statistical Package for Social Scientists (SPSS 21, 2012) for Windows. The results were evaluated by employing means, standard deviations, Pearson Correlation Coefficients, and a series of multiple linear regression analysis.

\section{RESULTS}

Table 1 offers classification of sub-categories of burnout and self-efficacy scales and their associated Cronbach Alpha internal consistency reliability coefficients based on the data gathered from the 10 participants of the study.

Table 1. Classification of different items of burnout and self-efficacy scales, Cronbach Alpha coefficients $(\alpha)$

\begin{tabular}{|llc|}
\hline Scales/sub-scales & \multicolumn{1}{c|}{ Items } & $(\alpha)$ \\
\hline Burnout & & 0.85 \\
Emotional Exhaustion & $1,4,9,10,15,16,18,20,22$ & 0.76 \\
Reduced Personal Accomplishment & $3,6,7,12,13,17,19,21$ & 0.69 \\
Depersonalization & $2,5,8,11,14$ & 0.95 \\
Self-efficacy & & 0.81 \\
Efficacy to Influence Decision Making & 1,2 & 0.79 \\
Instructional Efficacy & $3,4,5,6,7,8,9,10,11,12,13,14,15,16,17$ & 0.86 \\
Disciplinary Efficacy & 18,19 & 0.75 \\
Efficacy to Enlist Parental & & $20,21,22$ \\
and Community Involvement & $23,24,25,26,27,28,29,30$ & \\
Efficacy to Create a Positive School Climate & \\
\hline
\end{tabular}


In order to provide an answer to the research question, efficacy-burnout relationship was examined separately for emotional exhaustion, depersonalization, and personal accomplishment. The results of the analyses are presented in Tables 2-4 and are discussed in the following sections. As shown in Table 2, teachers' self-efficacy was negatively associated with emotional exhaustion.

Table 2. Correlations results for teachers' self-efficacy and emotional exhaustion

\begin{tabular}{|c|c|c|c|}
\hline & & Efficacy & Emotional exhaustion \\
\hline \multirow[t]{3}{*}{ Efficacy } & Pearson Correlation & 1 & $-.524^{* *}$ \\
\hline & Sig. (2-tailed) & & .036 \\
\hline & $\mathrm{N}$ & 10 & 10 \\
\hline \multirow[t]{3}{*}{ Emotional exhaustion } & Pearson Correlation & $-.524^{* *}$ & 1 \\
\hline & Sig. (2-tailed) & .036 & \\
\hline & $\mathrm{N}$ & 10 & 10 \\
\hline
\end{tabular}

**. Correlation is significant at the 0.05 level (2-tailed).

Analyses for the relationship between teachers' sense of efficacy and depersonalization are reported in Table 3. As shown in the Table, self-efficacy was negatively associated with depersonalization, yielding a significant but weak relationship.

Table 3. Correlations results for teachers' self-efficacy and depersonalization

\begin{tabular}{llrr}
\hline & & Efficacy & Depersonalization \\
\hline Efficacy & Pearson Correlation & 1 & $-.367^{* *}$ \\
\cline { 2 - 4 } & Sig. (2-tailed) & & .028 \\
\cline { 2 - 4 } & $\mathrm{N}$ & 10 & 10 \\
\hline Depersonalization & Pearson Correlation & $-.367^{* *}$ & 1 \\
\cline { 2 - 4 } & Sig. (2-tailed) & .028 & 10 \\
\cline { 2 - 4 } & $\mathrm{N}$ & 10 & \\
\hline
\end{tabular}

**. Correlation is significant at the 0.05 level (2-tailed).

Analyses examining the relationships between efficacy and personal accomplishment are presented in Table 4. As shown in the table, teachers' efficacy was positively related to personal accomplishment.

Table 4. Correlations results for teachers' self-efficacy and personal accomplishment

\begin{tabular}{llrr}
\hline & & Personal accomplishment & Efficacy \\
\hline Personal accomplishment & Pearson Correlation & 1 & $.333^{* *}$ \\
\cline { 2 - 4 } & Sig. (2-tailed) & 10 & .013 \\
\cline { 2 - 4 } & $\mathrm{N}$ & $.333^{* *}$ & 10 \\
\hline Efficacy & Pearson Correlation & .013 & 1 \\
\cline { 2 - 4 } & Sig. (2-tailed) & 10 & 10 \\
\cline { 2 - 4 } & $\mathrm{N}$ & & \\
\hline
\end{tabular}

**. Correlation is significant at the 0.05 level (2-tailed).

\section{DISCUSSION}

The aim of the present study was to find relationship between self-efficacy and burnout among EFL teachers at university setting. In line with the previous theoretical studies on the role of selfefficacy in burnout, the results of the present study indicated significant negative relationship between teacher self-efficacy and burnout. The size of this correlation shows that the higher the teachers' self-efficacy, the less likely they are to experience burnout. Bandura (1997) mentioned that a strong sense of self-efficacy enhances human accomplishments and personal success in many 
ways including the ability to cope with stressful situations. Similarly, in the case of teaching at universities, teachers who feel more successful in their profession are more likely to handle various sources of stress (e.g. job insecurity, students' low motivation. Work overload). Further, Brouwers and Tomic (2000) in a cross-sectional study among teachers approved that teachers' self-efficacy beliefs about classroom management were remarkably relevant to their burnout level.

\section{CONCLUSION}

The findings additionally indicated that all five constructs of self-efficacy were contrarily correlated with teacher burnout. Besides, a positive teaching climate which is supportive and respectful of teacher was negatively related to teacher burnout and stress. On the other hand, when teachers are prevented from having hesitations on teacher related issues, they tend to be more efficacious. In addition, teachers with a low sense of classroom efficacy, tend to become easily intolerant and aggressive towards students' misbehavior. Such teachers usually underestimate students' ability to enhance on education and consequently, they tend to focus on content of study rather than students development (Friedman, \& Faber, 1992).

Generally speaking, the findings highlight the importance of establishing courses for EFL teachers to increase efficacy. In order to manage teacher burnout, EFL teachers ought to acquire skills to control their stress levels. Language administrators also play significant role in this issue. The sources ad side-effects of teacher stress can be discussed. Colleagues, chancellors, and others can provide assistance and support for stressed-teachers. Undoubtedly, a positive and supportive educational environment helps teachers' success. Further research is needed to incorporate a link of teachers in university settings and private institutions. The teachers studied in this research were from university setting.

\section{References}

[1] Bandura, A. (1997). Self-efficacy: The exercise of control. New York: W.H. Freeman.

[2] Bandura, A. (2006). Adolescent development from an agentic perspective. In F. Pajares, \& T. Urdan (Eds.), Self-efficacy beliefs of adolescents (pp.1-43). Greenwich, Connecticut: Information Age Publishing.

[3] Brouwers, A., \&Tomic, W. (2000). A longitudinal study of teacher burnout and perceived selfefficacy in classroom management. Teaching and Teacher Education, 16, 239-253.

[4] Chwalisz, K., Altmaier, E. M., \& Russell, D. W. (1992). Causal attributions, self-efficacy cognitions, and coping with stress. Journal of Social and Clinical Psychology, 11, 377-400

[5] Friedman, I. A., \& Farber, B. A. (1992).Professional self-concept as a predictor of teacher burnout. Journal of Educational Research, 86, 28-35.

[6] Jennett, H. K., Harris, S. L., \& Mesibov, G. B. (2003).Commitment to philosophy, teacher efficacy, and burnout among teachers of children with autism. Journal of Autism and Developmental Disorders, 33, 583-593

[7] Maslach, C., \& Jackson, S. E. (1981). Maslach burnout inventory manual. Mountain View, California: CPP, Inc.

[8] Maslach, C., \& Jackson, S. E. (1986). Maslach burnout inventory manual (2nd ed.). Palo Alto, CA: Consulting Psychologist Press.

[9] Maslach, C., Jackson S. E., \& Leiter M. P. (1996). Maslach Burnout Inventory Manual. Palo Alto (CA): Consulting Psychologist Press.

[10] Schaufeli, W. B. \& Van Dierendonck, D. (1993). The construct validity of two burnout measures. Journal of Organizational Behaviour, 14, 631-647.

[11] Woolfolk, A. E., \& Hoy, W. K. (1990). Prospective teachers' sense of efficacy and beliefs about control. Journal of Educational Psychology, 82, 81-91. 